Article

\title{
Real-World Implications of Nonbiological Factors with Staging, Prognosis and Clinical Management in Colon Cancer
}

\author{
Qi Liu ${ }^{1,2}$, Dakui Luo ${ }^{1,2}$, Sanjun Cai ${ }^{1,2}$, Qingguo Li ${ }^{1,2, *}$ and Xinxiang Li 1,2,* (D) \\ 1 Department of Colorectal Surgery, Fudan University Shanghai Cancer Center, Shanghai 200032, China; \\ LQ671993@163.com (Q.L.); 15262905600@163.com (D.L.); 16211230008@fudan.edu.cn (S.C.) \\ 2 Department of Oncology, Shanghai Medical College, Fudan University, Shanghai 200032, China \\ * Correspondence: oncosurgeonli@sohu.com (Q.L.); 11491xx@sina.com (X.L.)
}

Received: 3 July 2018; Accepted: 6 August 2018; Published: 8 August 2018

\begin{abstract}
Background: The present study analyzed the nonbiological factors (NBFs) together with the American Joint Committee on Cancer (AJCC) Tumor-Node-Metastasis (TNM) staging system to generate a refined, risk-adapted stage for the clinical treatment of colon cancer. Methods: Eligible patients $(N=28,818)$ with colon cancer between 1 January 2010 and 31 December 2014, were identified from the Surveillance, Epidemiology, and End Results (SEER) database. Kaplan-Meier curves and Cox proportional hazards regression, analyzed the probabilities of cancer-specific survival (CSS) in patients with colon cancer, with different NBF-TNM stages. Results: Insurance status, marital status, and median household income were significant prognostic NBFs in the current study $(p<0.05)$. The concordance index of NBF-TNM stage was 0.857 (95\% confidence interval $(\mathrm{CI})=0.8472-0.8668)$. Multivariate Cox analyses, indicated that NBF1-stage was independently associated with a $50.4 \%$ increased risk of cancer-specific mortality in colon cancer $(p<0.001)$, which increased to $77.1 \%$ in non-metastatic colon cancer. NBF0-stage improved in CSS as compared to the NBF1-stage in the respective stages $(p<0.05)$. Conclusions: The new proposed NBF-stage was an independent prognostic factor in colon cancer. Effect of NBFs on the survival of colon cancer necessitates further clinical attention. Moreover, the incorporation of NBF-stage into the AJCC TNM staging system is essential for prognostic prediction, and clinical guidance of adjuvant chemotherapy in stage II and III colon cancer.
\end{abstract}

Keywords: non-biological factors; AJCC TNM staging system; prognostication; colon cancer; SEER

\section{Introduction}

Colon cancer is one of the most common malignancies and its increasing incidence has been noted over the years in the USA [1]. The prognosis of patients with malignant colon cancer is influenced both by disease factors and patient-related factors, including biological factors and nonbiological factors (NBFs). The effect of different biological factors, such as American Joint Committee on Cancer (AJCC) staging system, microsatellite instability (MSI) status, and tumor grade on the survival of patients with colon cancer has been widely studied [2-4]. Several studies have demonstrated that NBFs, such as marital status [5,6], health insurance [7,8], and employment [9] were associated with the survival of patients with colon cancer. However, to the best of our knowledge, NBFs have not yet been studied together in the prognosis of colon cancer. The prognostication of AJCC staging system is only based on the invasion extent of the primary tumor (T stage), lymph node status ( $\mathrm{N}$ stage), and distant spread (M stage) [10]. It is not perfect for prognostic prediction and clinical management, and a better prognostic staging system combined with AJCC staging system and other prognostic factors is needed [10-12]. 
Herein, we conducted a large population-based study to analyze the effect of different NBFs, such as employment, education, income, health insurance, year of diagnosis, and marital status on survival in colon cancer cases. Thus, we proposed and evaluated a novel NBF-TNM stage (i.e., combination of AJCC staging system and NBF stage), with respect to the prediction of prognosis and clinical management.

\section{Patients and Methods}

Ethics Statement: This study was based on public data from the freely available SEER database and was approved by the Ethical Committee and Institutional Review Board of the Fudan University Shanghai Cancer Center. We obtained permission to access research data files with the reference number 10782-Nov2016 and the permission date was 8 April 2017. The data did not include the use of human subjects or personal identifying information and no informed consent was required for this study.

\subsection{Study Design and Data Source}

The Surveillance, Epidemiology, and End Results (SEER) database is an authoritative source of information on cancer incidence and survival in the USA. It is a comprehensive source of population-based information, including all the newly diagnosed cancer cases occurring in individuals residing in SEER-participating areas, encompassing approximately $28 \%$ of the American population.

Using the SEER-Stat software (SEER ${ }^{*}$ Stat 8.3.4, https://seer.cancer.gov/seerstat/software/), patients diagnosed with colon cancer between 1 January 2010 and 31 December 2014, from the SEER Program of the National Cancer Institute were identified, as shown in Figure 1.

Colon cancer patients at SEER 18 registries between January 1, 2010, and December 31, 2014. $(N=129954)$

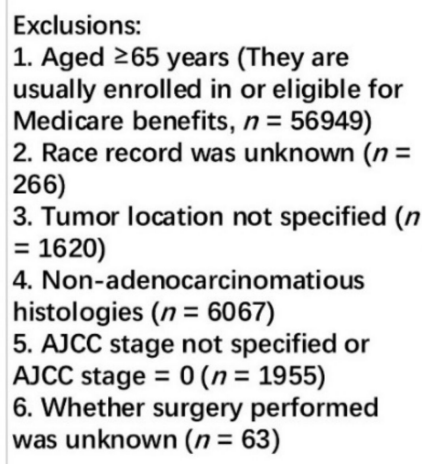

Figure 1. Flow diagram of patient population selected from Surveillance, Epidemiology, and End Results (SEER) database. 
Among these patients with colon cancer, those with known NBFs (including marital status, insurance status, county-level median household income, county percentage with a bachelor's degree, unemployment situation, and year of diagnosis) were included in our analyses. Considering that the insurance status was included in our analyses as an NBF, patients whose age at diagnosis $\geq 65$ years were excluded from the population, as most of them were eligible for Medicare benefits. Patients with unknown race, unspecified tumor location, non-adenocarcinomatous histology, unspecified seventh AJCC stage, and those with seventh AJCC stage $=0$ or whether surgery performed was unknown, were also excluded from the current analyses.

\subsection{NBF Stage and Statistical Analysis}

Cox proportional hazards models were established to identify the independent prognostic variables at a median survival time of 21 (range, 0-59) months. The hazard ratios were shown with 95\% confidence intervals (CIs). Thus, we conducted a multivariate Cox proportional hazard regression analysis of all the prognostic factors associated with $p$-value $<0.2$ in the univariate analysis, including the NBFs (marital status, insurance status, county-level median household income, county percentage with a bachelor's degree, unemployment situation, and year of diagnosis). The results showed that marital status, insurance status, and county-level median household income were significant prognostic NBFs of CSS in colon cancer.

As shown in Figure 2, patients were stratified based on the prognostic score incorporating the three NBFs. First, we considered the point of each group of NBFs equivalent, to the value of the hazard ratios. Then, the total prognostic score of each patient was calculated as the sum of the points in the three NBFs. For example, a married and uninsured colon cancer patient whose county-level median household income was 48.58-55.87 K (dollars), the score was calculated as the sum of " 1.150 ", "1.620", and "1.000" which equaled to "3.770". The total scores ranged from 3.000-3.981, followed by a comprehensive prognostic score based on the three NBFs, which was 3.000 with optimal prognosis and those with a score of 3.981 had the worst prognosis. The distribution and associations of different score subgroups, are shown in Figure 3. Finally, the prognostic score was divided into two groups, and the cut-off point was the median value of the prognostic score of the whole population. The higher score was assigned to stage NBF1, while the other was assigned to stage NBF0.

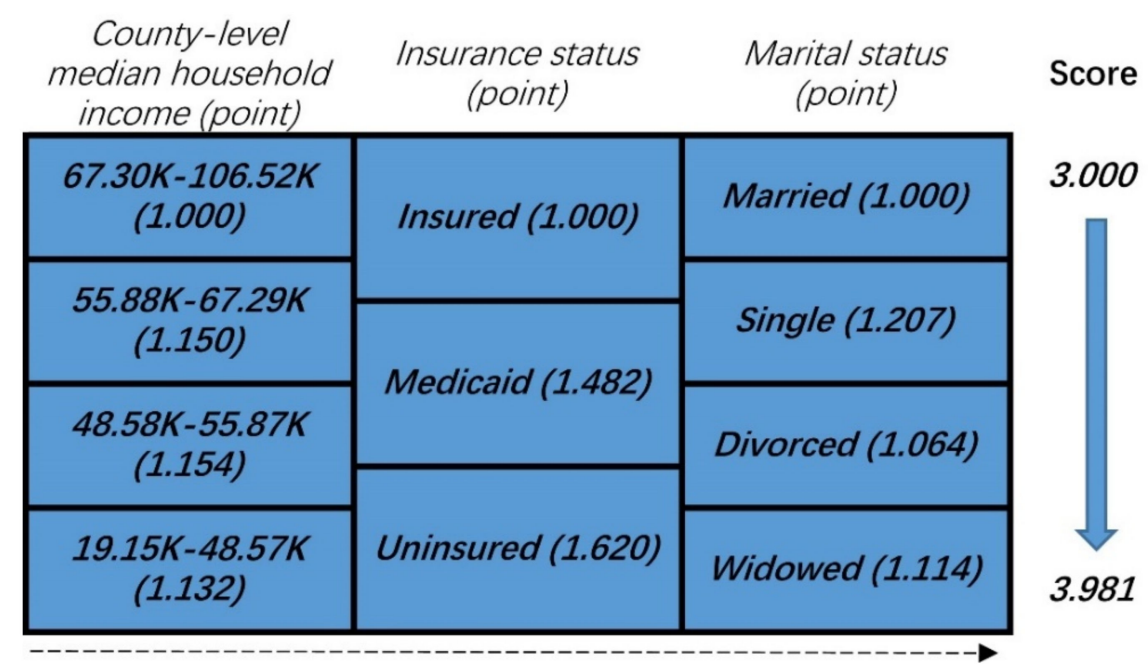

Figure 2. Patient prognostic score in colon cancer: risk-stratifications. 


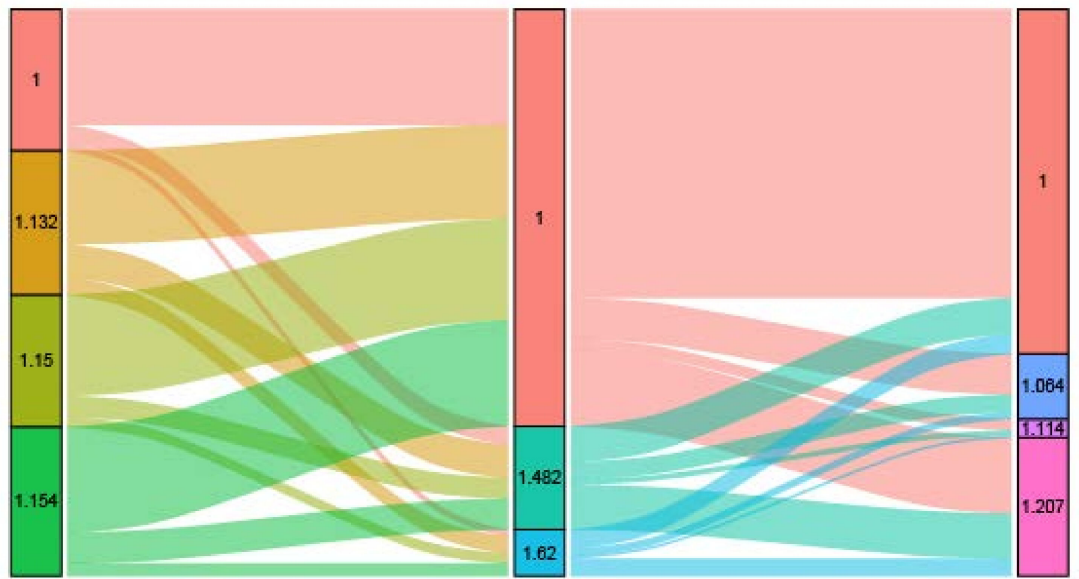

Figure 3. Graphical summary of the distribution and associations of different score subgroups in county-level median household income, insurance status and marital status, respectively.

Multivariate Cox proportional hazard regression analysis determined the prognosis of NBF stage, and the combination of AJCC TNM staging system and NBF stage (TNM-N stage). The endpoint used for comparison in the present study was CSS. The Kaplan-Meier survival curves were used to evaluate the prognostic prediction of different factors and the log-rank tests, to assess the statistical significance. A $p$-value $<0.05$ was considered statistically significant. The statistical analysis was performed using the Statistical Package for Social Science (SPSS version 22; IBM Corporation, Armonk, NY, USA).

\section{Results}

A total of 28,818 patients were diagnosed with colon cancer between 1 January 2010 and 31 December 2014, from the SEER Program. The median follow-up time was 21 (range, 0-59) months. At the end of the follow-up time, $4404(15.3 \%)$ patients had died of colon cancer. The baseline characteristics of colon cancer patients included in the current study were summarized in Table 1.

Table 1. Baseline characteristics of colon cancer patients included in our study.

\begin{tabular}{|c|c|c|}
\hline \multicolumn{2}{|c|}{ Characteristic } & \multirow{2}{*}{$\frac{\text { No. (\%) }}{21,179(73.5)}$} \\
\hline \multirow{3}{*}{ Race } & White & \\
\hline & Black & 4706 (16.3) \\
\hline & Other & $2933(10.2)$ \\
\hline \multirow{2}{*}{ Gender } & Male & $15,402(53.4)$ \\
\hline & Female & $13,416(46.6)$ \\
\hline \multirow{8}{*}{ Tumor location } & Appendix & $359(1.2)$ \\
\hline & Cecum & $5276(18.3)$ \\
\hline & Ascending colon & $4703(16.3)$ \\
\hline & Hepatic flexure & $1165(4.0)$ \\
\hline & Transverse colon & $2538(8.8)$ \\
\hline & Splenic flexure & $1062(3.7)$ \\
\hline & Descending colon & $2350(8.2)$ \\
\hline & Sigmoid Colon & $11,365(39.4)$ \\
\hline \multirow{5}{*}{ Tumor grade } & Grade I & $2360(8.2)$ \\
\hline & Grade II & $19,568(67.9)$ \\
\hline & Grade III & 4103 (14.2) \\
\hline & Grade IV & $723(2.5)$ \\
\hline & Unknown & $2064(7.2)$ \\
\hline
\end{tabular}


Table 1. Cont

\begin{tabular}{|c|c|c|}
\hline \multicolumn{2}{|c|}{ Characteristic } & \multirow{2}{*}{$\begin{array}{c}\text { No. (\%) } \\
6926(24.0)\end{array}$} \\
\hline \multirow{9}{*}{ AJCC stage } & I & \\
\hline & IIA & 5645 (19.6) \\
\hline & IIB & $589(2.0)$ \\
\hline & IIC & $546(1.9)$ \\
\hline & IIIA & $1182(4.1)$ \\
\hline & IIIB & $5323(18.5)$ \\
\hline & IIIC & $1938(6.7)$ \\
\hline & IVA & $3461(12.0)$ \\
\hline & IVB & $3208(11.1)$ \\
\hline \multirow{2}{*}{ Surgery } & Surgery performed & $26,296(91.2)$ \\
\hline & Surgery not performed & $2522(8.8)$ \\
\hline \multirow{4}{*}{ County $\%$ with bachelor degree } & $5.95-20.77 \%$ & $7070(24.5)$ \\
\hline & $20.78-29.91 \%$ & $5826(20.2)$ \\
\hline & $29.92-35.57 \%$ & $8689(30.2)$ \\
\hline & $35.58-64.01 \%$ & $7233(25.1)$ \\
\hline \multirow{4}{*}{$\begin{array}{l}\text { County-level median household } \\
\text { income }^{\#}\end{array}$} & $19.15-48.57 \mathrm{~K}$ & $7180(24.9)$ \\
\hline & $48.58-55.87 \mathrm{~K}$ & $6719(23.3)$ \\
\hline & $55.88-67.29 \mathrm{~K}$ & $7587(26.3)$ \\
\hline & $67.30-106.52 \mathrm{~K}$ & $7332(25.4)$ \\
\hline \multirow{4}{*}{ County $\%$ were unemployed } & $1.92-8.66 \%$ & $7180(24.9)$ \\
\hline & $8.67-9.60 \%$ & $6719(23.3)$ \\
\hline & $9.61-11.27 \%$ & $7587(26.3)$ \\
\hline & $11.28-21.21 \%$ & $7332(25.4)$ \\
\hline \multirow{5}{*}{ Year of diagnosis } & 2010 & $5757(20.0)$ \\
\hline & 2011 & $5634(19.6)$ \\
\hline & 2012 & $5596(19.4)$ \\
\hline & 2013 & $5773(20.0)$ \\
\hline & 2014 & $6058(21.0)$ \\
\hline \multirow{3}{*}{ Tumor size } & $\leq 5 \mathrm{~cm}$ & $16,409(56.9)$ \\
\hline & $>5 \mathrm{~cm}$ & 8409 (29.2) \\
\hline & Unknown & 4000 (13.9) \\
\hline \multirow{4}{*}{ Age at diagnosis (years) } & $\leq 50$ & 8245 (28.6) \\
\hline & $51-55$ & $6313(21.9)$ \\
\hline & $56-60$ & $7335(25.5)$ \\
\hline & $\geq 61$ & $6925(24.0)$ \\
\hline \multirow{3}{*}{ Insurance status } & Insured & $21,198(73.6)$ \\
\hline & Medicaid & $5258(18.2)$ \\
\hline & Uninsured & $2362(8.2)$ \\
\hline \multirow{4}{*}{ Marital status } & Married & $17,515(60.8)$ \\
\hline & Single & $7040(24.4)$ \\
\hline & Divorced & $3321(11.5)$ \\
\hline & Widowed & $942(3.3)$ \\
\hline
\end{tabular}

\# Shown in US dollars.

\subsection{Three NBFs Were Strongly Associated with CSS of Colon Cancer}

Univariate analysis demonstrated that race, gender, tumor location, tumor grade, AJCC stage, surgery, insurance status, marital status, tumor size, age at diagnosis, county percentage with bachelor's degree, county-level median household income, and county percentage of unemployed were associated with CSS $(p<0.2)$. These factors were included in the multivariate Cox hazard regression analysis, and the result showed that NBFs such as insurance status, marital status, and county-level median household income were independently associated with CSS (Table 2). Other 
factors identified as independent protective factors included race, gender, tumor location, tumor grade, AJCC stage, surgery, tumor size, and age at diagnosis.

Table 2. Multivariate Cox regression analyses of CSS.

\begin{tabular}{|c|c|c|c|c|c|}
\hline \multirow{2}{*}{ Variable } & \multirow{2}{*}{ Reference } & \multirow{2}{*}{ Characteristic } & \multicolumn{3}{|c|}{ Cancer-Specific Survival } \\
\hline & & & HR (95\%) & SE & $p$ Value \\
\hline \multirow[t]{2}{*}{ Race } & \multirow[t]{2}{*}{ White } & Black & $1.179(1.089-1.275)$ & 0.040 & $<0.001$ \\
\hline & & Other & $1.046(0.941-1.162)$ & 0.054 & 0.405 \\
\hline Gender & Male & Female & $0.851(0.801-0.904)$ & 0.031 & $<0.001$ \\
\hline \multirow[t]{7}{*}{ Tumor location } & \multirow[t]{7}{*}{ Appendix } & Cecum & $0.871(0.682-1.113)$ & 0.125 & 0.270 \\
\hline & & Ascending colon & $0.864(0.675-1.107)$ & 0.126 & 0.249 \\
\hline & & Hepatic flexure & $0.859(0.652-1.132)$ & 0.141 & 0.281 \\
\hline & & Transverse colon & $0.811(0.626-1.050)$ & 0.132 & 0.112 \\
\hline & & Splenic flexure & $0.773(0.585-1.023)$ & 0.143 & 0.072 \\
\hline & & Descending colon & $0.670(0.516-0.869)$ & 0.133 & 0.003 \\
\hline & & Sigmoid Colon & $0.620(0.487-0.791)$ & 0.124 & $<0.001$ \\
\hline \multirow[t]{4}{*}{ Tumor grade } & \multirow[t]{4}{*}{ Grade I } & Grade II & $1.042(0.892-1.217)$ & 0.079 & 0.601 \\
\hline & & Grade III & $1.720(1.461-2.025)$ & 0.083 & $<0.001$ \\
\hline & & Grade IV & $2.111(1.716-2.596)$ & 0.106 & $<0.001$ \\
\hline & & Unknown & $1.164(0.980-1.382)$ & 0.088 & 0.083 \\
\hline \multirow[t]{8}{*}{ AJCC stage } & \multirow[t]{8}{*}{ I } & IIA & $2.266(1.738-2.955)$ & 0.135 & $<0.001$ \\
\hline & & IIB & $6.547(4.614-9.291)$ & 0.179 & $<0.001$ \\
\hline & & IIC & $9.819(7.124-13.535)$ & 0.164 & $<0.001$ \\
\hline & & IIIA & 1.864 (1.199-2.899) & 0.225 & 0.006 \\
\hline & & IIIB & $5.600(4.399-7.129)$ & 0.123 & $<0.001$ \\
\hline & & IIIC & $16.630(13.051-21.192)$ & 0.124 & $<0.001$ \\
\hline & & IVA & $39.280(31.324-49.257)$ & 0.115 & $<0.001$ \\
\hline & & IVB & $54.228(43.145-68.159)$ & 0.117 & $<0.001$ \\
\hline Surgery & Surgery performed & Surgery not performed & $2.649(2.417-2.903)$ & 0.047 & $<0.001$ \\
\hline \multirow[t]{2}{*}{ Insurance status } & \multirow[t]{2}{*}{ Insured } & Medicaid & $1.482(1.376-1.597)$ & 0.038 & $<0.001$ \\
\hline & & Uninsured & $1.620(1.476-1.778)$ & 0.048 & $<0.001$ \\
\hline \multirow[t]{3}{*}{ Marital status } & \multirow[t]{3}{*}{ Married } & Single & 1.207 (1.123-1.297) & 0.037 & $<0.001$ \\
\hline & & Divorced & $1.064(0.969-1.169)$ & 0.048 & 0.195 \\
\hline & & Widowed & $1.114(0.945-1.314)$ & 0.084 & 0.199 \\
\hline \multirow[t]{2}{*}{ Tumor size } & \multirow[t]{2}{*}{$\leq 5 \mathrm{~cm}$} & $>5 \mathrm{~cm}$ & $1.157(1.080-1.240)$ & 0.035 & $<0.001$ \\
\hline & & Unknown & $1.187(1.082-1.302)$ & 0.047 & $<0.001$ \\
\hline \multirow{3}{*}{$\begin{array}{l}\text { Age at diagnosis } \\
\text { (years) }\end{array}$} & \multirow[t]{3}{*}{$\leq 50$} & $51-55$ & $1.078(0.988-1.175)$ & 0.044 & 0.092 \\
\hline & & $56-60$ & $1.188(1.096-1.288)$ & 0.041 & $<0.001$ \\
\hline & & $\geq 61$ & $1.338(1.232-1.452)$ & 0.042 & $<0.001$ \\
\hline \multirow{3}{*}{$\begin{array}{l}\text { County \% with } \\
\text { bachelor degree }\end{array}$} & \multirow[t]{3}{*}{$35.58-64.01 \%$} & $29.92-35.57 \%$ & $1.017(0.918-1.127)$ & 0.052 & 0.745 \\
\hline & & $20.78-29.91 \%$ & 1.035 (0.926-1.157) & 0.057 & 0.547 \\
\hline & & $5.95-20.77 \%$ & $1.138(1.005-1.289)$ & 0.063 & 0.041 \\
\hline \multirow{3}{*}{$\begin{array}{l}\text { County-level median } \\
\text { household income }\end{array}$} & \multirow[t]{3}{*}{$67.30-106.52 \mathrm{~K}$} & $55.88-67.29 \mathrm{~K}$ & $1.150(1.037-1.276)$ & 0.053 & 0.008 \\
\hline & & $48.58-55.87 \mathrm{~K}$ & $1.154(1.027-1.297)$ & 0.060 & 0.016 \\
\hline & & $19.15-48.57 \mathrm{~K}$ & $1.132(1.001-1.281)$ & 0.063 & 0.048 \\
\hline & $1.92-8.66 \%$ & $8.67-9.60 \%$ & $1.074(0.984-1.171)$ & 0.044 & 0.110 \\
\hline county $\%$ were & & $9.61-11.27 \%$ & $1.014(0.922-1.115)$ & 0.049 & 0.771 \\
\hline & & $11.28-21.21 \%$ & $1.062(0.968-1.265)$ & 0.047 & 0.201 \\
\hline
\end{tabular}

\subsection{NBF Stage Was Strongly Associated with CSS in Colon Cancer}

NBF0-stage was assigned to 15,326 patients (53.2\%) and NBF1-stage was assigned to 13,492 patients (46.8\%). Multivariable analysis showed that the NBF1 was independently associated with CSS of 28,818 patients with colon cancer, with a $50.4 \%$ increased risk of cancer-specific mortality (hazard ratio $(\mathrm{HR})=1.504,95 \% \mathrm{CI}$ : 1.415-1.600, $p<0.001$; Table 3). A multivariable Cox analysis was also conducted in patients with non-metastatic colon cancer $(n=22,149)$, on the overall cohort, which also substantiated that the NBF stage was independently associated with an increased risk of CSS. In patients with non-metastatic colon cancer, a 77.1\% increased risk of cancer-specific mortality was observed $(\mathrm{HR}=1.771,95 \%$ CI: 1.569-2.000, $p<0.001$; Supplementary Table S1), which was higher than 
that in the overall cohort, indicating that the prognostic prediction efficacy of NBF stage improved in patients with AJCC stage I-III colon cancer.

Table 3. Multivariable Cox regression analyses of independent prognostic factors in colon cancer.

\begin{tabular}{|c|c|c|c|c|c|}
\hline \multirow{2}{*}{ Variable } & \multirow{2}{*}{ Reference } & \multirow{2}{*}{ Characteristic } & \multicolumn{3}{|c|}{ Cancer-Specific Survival } \\
\hline & & & HR $(95 \%)$ & SE & $p$ Value \\
\hline \multirow[t]{2}{*}{ Race } & \multirow[t]{2}{*}{ White } & Black & 1.210 (1.121-1.307) & 0.039 & $<0.001$ \\
\hline & & Other & $1.038(0.936-1.152)$ & 0.053 & 0.477 \\
\hline Gender & Male & Female & $0.842(0.793-0.894)$ & 0.031 & $<0.001$ \\
\hline \multirow[t]{7}{*}{ Tumor location } & \multirow[t]{7}{*}{ Appendix } & Cecum & $0.897(0.702-1.146)$ & 0.125 & 0.386 \\
\hline & & Ascending colon & $1.881(0.688-1.129)$ & 0.126 & 0.317 \\
\hline & & Hepatic flexure & $0.878(0.667-1.156)$ & 0.140 & 0.353 \\
\hline & & Transverse colon & $0.824(0.637-1.067)$ & 0.132 & 0.143 \\
\hline & & Splenic flexure & 0.785 (0.594-1.038) & 0.143 & 0.09 \\
\hline & & Descending colon & $0.680(0.524-0.882)$ & 0.133 & 0.004 \\
\hline & & Sigmoid Colon & $0.637(0.500-0.811)$ & 0.124 & $<0.001$ \\
\hline \multirow[t]{4}{*}{ Tumor grade } & \multirow[t]{4}{*}{ Grade I; } & Grade II & 1.027 (0.879-1.199) & 0.079 & 0.737 \\
\hline & & Grade III & 1.698 (1.443-1.999) & 0.083 & $<0.001$ \\
\hline & & Grade IV & $2.076(1.688-2.554)$ & 0.106 & $<0.001$ \\
\hline & & Unknown & $1.152(0.970-1.368)$ & 0.088 & 0.106 \\
\hline Surgery & Surgery performed & Surgery not performed & $2.632(2.402-2.884)$ & 0.047 & $<0.001$ \\
\hline \multirow[t]{2}{*}{ Tumor size } & \multirow[t]{2}{*}{$\leq 5 \mathrm{~cm}$} & $>5 \mathrm{~cm}$ & $1.169(1.090-1.252)$ & 0.035 & $<0.001$ \\
\hline & & Unknown & $1.186(1.081-1.300)$ & 0.047 & $<0.001$ \\
\hline \multirow{3}{*}{$\begin{array}{l}\text { Age at diagnosis } \\
\text { (years) }\end{array}$} & \multirow[t]{3}{*}{$\leq 50$} & $51-55$ & $1.086(0.995-1.184)$ & 0.044 & 0.063 \\
\hline & & $56-60$ & $1.189(1.097-1.289)$ & 0.041 & $<0.001$ \\
\hline & & $\geq 61$ & $1.340(1.236-1.454)$ & 0.041 & $<0.001$ \\
\hline \multirow{3}{*}{$\begin{array}{l}\text { County \% with } \\
\text { bachelor degree }\end{array}$} & \multirow[t]{3}{*}{$5.95-20.77 \%$} & $20.78-29.91 \%$ & $1.072(0.978-1.176)$ & 0.047 & 0.136 \\
\hline & & $29.92-35.57 \%$ & $1.119(1.021-1.228)$ & 0.047 & 0.017 \\
\hline & & $35.58-64.01 \%$ & $1.254(1.139-1.382)$ & 0.049 & $<0.001$ \\
\hline \multirow{3}{*}{$\begin{array}{l}\text { County \% were } \\
\text { unemployed }\end{array}$} & \multirow[t]{3}{*}{$1.92-8.66 \%$} & $8.67-9.60 \%$ & $1.090(1.000-1.188)$ & 0.044 & 0.050 \\
\hline & & $9.61-11.27 \%$ & $1.050(0.959-1.150)$ & 0.047 & 0.293 \\
\hline & & $11.28-21.21 \%$ & $1.075(0.981-1.178)$ & 0.047 & 0.121 \\
\hline \multirow[t]{8}{*}{ AJCC stage } & \multirow[t]{8}{*}{ I } & IIA & $2.296(1.761-2.994)$ & 0.135 & $<0.001$ \\
\hline & & IIB & $6.704(4.725-9.512)$ & 0.178 & $<0.001$ \\
\hline & & IIC & 9.979 (7.240-13.753) & 0.164 & $<0.001$ \\
\hline & & IIIA & $1.859(1.195-2.890)$ & 0.225 & 0.006 \\
\hline & & IIIB & $5.651(4.439-7.194)$ & 0.123 & $<0.001$ \\
\hline & & IIIC & 16.921 (13.279-21.562) & 0.124 & $<0.001$ \\
\hline & & IVA & $40.051(31.941-50.220)$ & 0.115 & $<0.001$ \\
\hline & & IVB & 55.404 (44.081-69.636) & 0.117 & $<0.001$ \\
\hline NBF stage & Stage 0 & Stage 1 & $1.504(1.415-1.600)$ & 0.031 & $<0.001$ \\
\hline
\end{tabular}

\subsection{Prognostic Prediction of NBF-TNM Stage}

The concordance index of NBF-TNM stage was 0.857 (95\% CI = 0.8472-0.8668). Kaplan-Meier CSS of all NBF-TNM stages (AJCC TNM staging system including I, IIA, IIB, IIC, IIIA, IIIB, IIIC, IVA, and IVB, combined with NBF 0 or NBF1 stage) was used for the analysis of the prognostic prediction of the NBF-TNM stage in the overall cohort $(n=28,818)$, as seen in Figure 4A,C. As expected, all NBF0-stage patients showed a statistically significant increased CSS as compared to the NBF1-stage patients $(p<0.05)$ in all the respective AJCC TNM stages.

Moreover, Figure 4A,C also shows an increased or not apparently different, 59-month CSS of stage NBF0-TNM patients as compared to stage NBF1-TNM patients with higher risk AJCC stages. For example, an increased CSS was found in stage IIA-NBF0 as compared to stage IIIA-NBF1 $(p<0.001)$. Similarly, we also noted a decreased CSS in stage IIB-NBF1 as compared to stage IIIB-NBF0 $(p<0.001)$, and not apparently different CSS in stage I-NBF1 as compared to stage III-NBF0 $(p=0.204)$. 

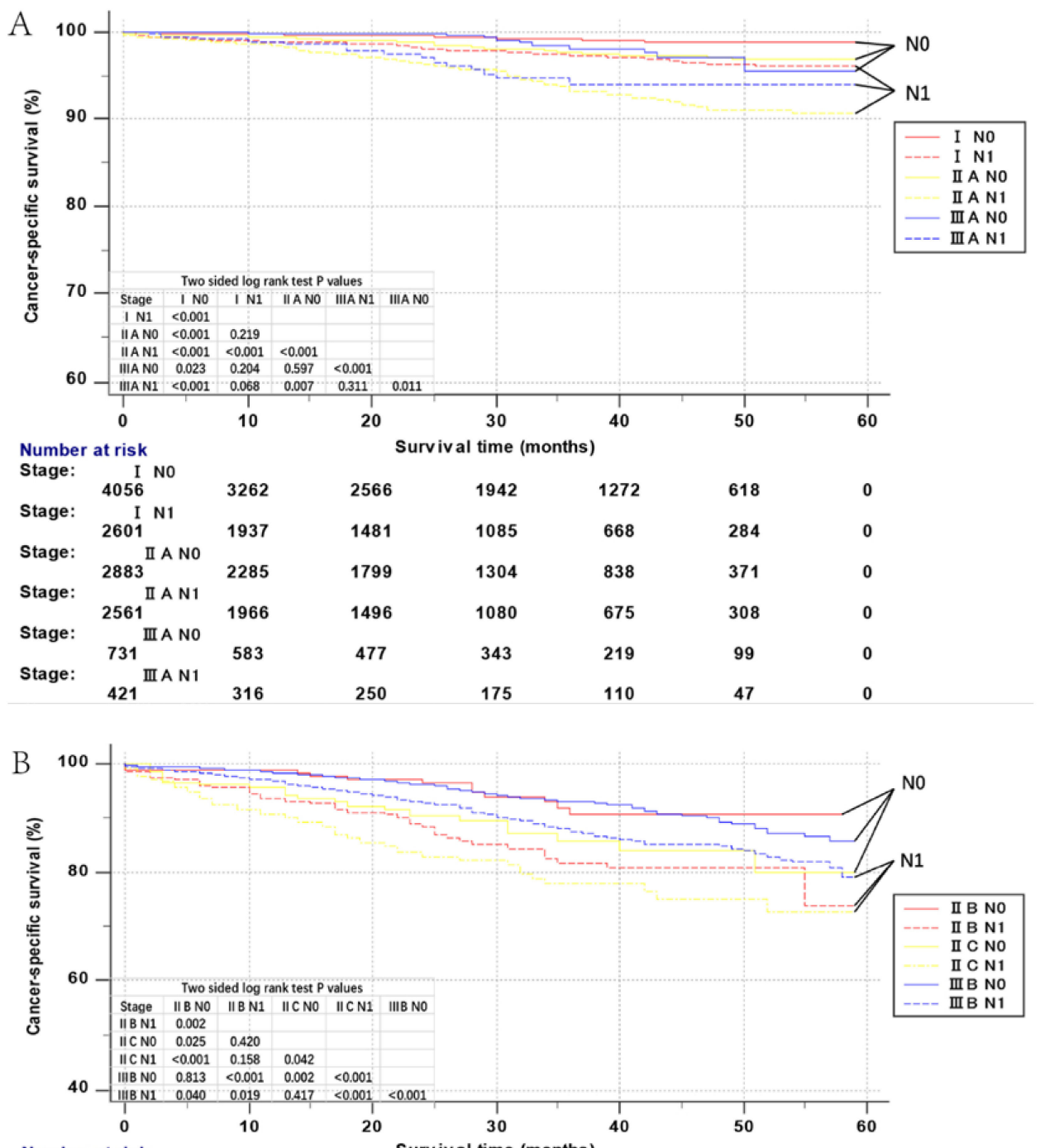

Number at risk Survival time (months)

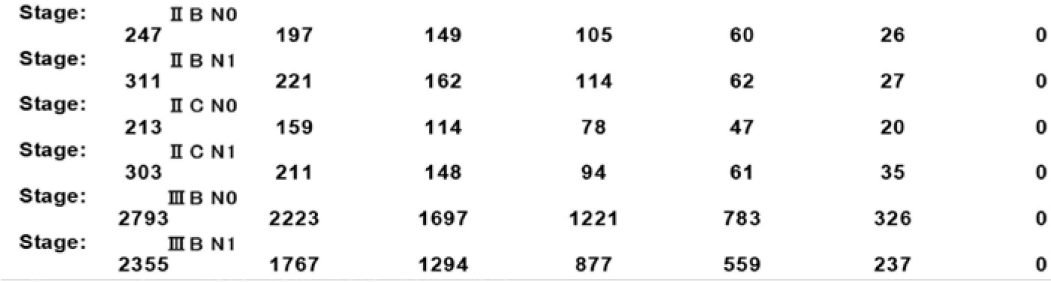

Figure 4. Cont. 


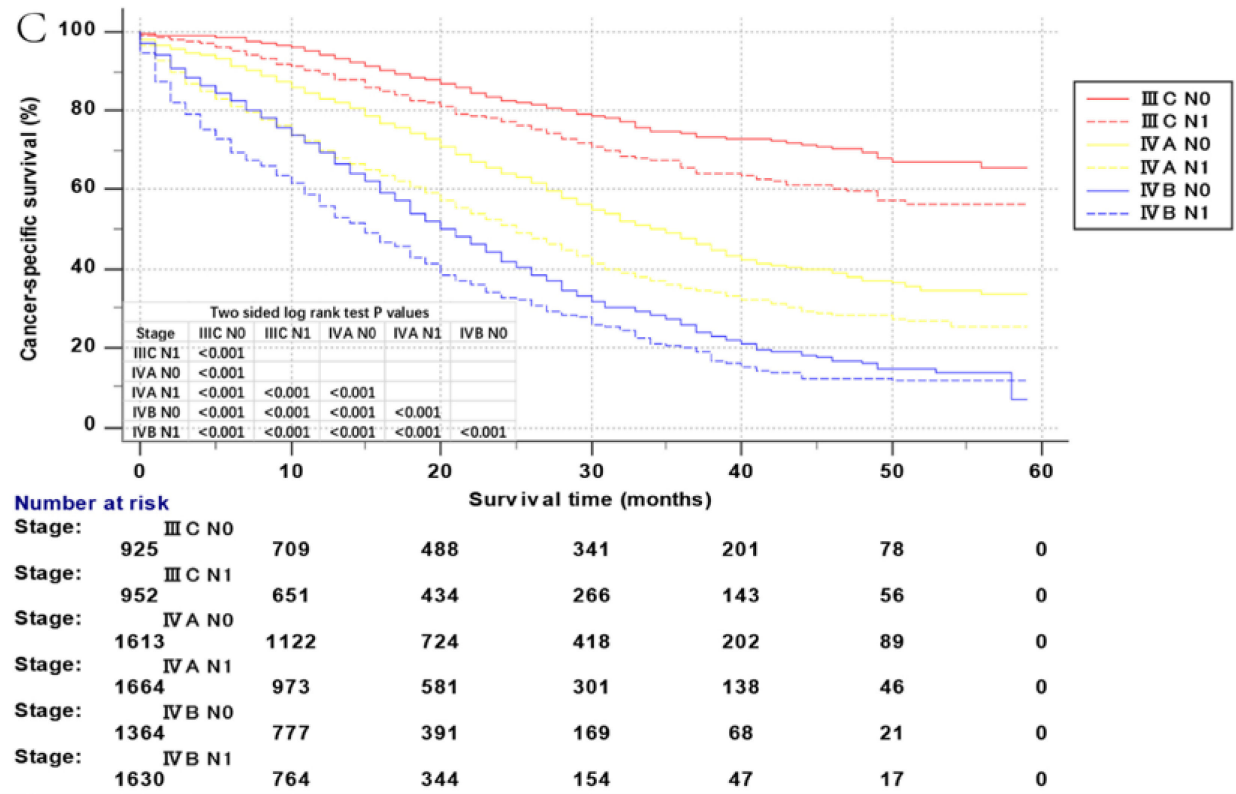

Figure 4. Kaplan-Meier survival curves of non-biological factor-Tumor-Node-Metastasis (NBF-TNM) staging system. (A) Cancer-specific survival (CSS) of I-N0 stage, I-N1 stage, IIA-N0 stage, IIA-N1 stage, IIIA-N0 stage, and IIIA-N1 stage. (B) CSS of IIB-N0 stage, IIB-N1 stage, IIC-N0 stage, IIC-N1 stage, IIIB-N0 stage, and IIIB-N1 stage. (C) CSS of IIIC-N0 stage, IIIC-N1 stage, IVA-N0 stage, IVA-N1 stage, IVB-N0 stage, and IVB-N1 stage.

The multivariate Cox regression analyses compared the HRs of each AJCC TNM stage and NBF-TNM stages. Consistent with the Kaplan-Meier survival curves, all the NBF0-TNM patients showed lower HRs as compared to the respective NBF1-TNM stages (Table 4). Notably, several node-positive stages (stage IIIA-NBF0, IIIA-NBF1, IIIB-NBF0, or IIIB-NBF1) had a better prognosis than that of several node-negative stages (stage IIC-NBF0, IIC-NBF1, or IIB-NBF1). In addition, HRs of several stages NBF1-TNM patients even exceeded stage NBF0-TNM patients, displaying higher risk by conventional AJCC TNM stages. For example, the cancer-specific mortality was higher in stage I-NBF1 patients (HR $=3.172,95 \%$ CI: 2.009-5.008) as compared to stage IIA-NBF0 (HR = 2.391, 95\% CI: 1.503-3.801), or IIIA-NBF0 patients (HR $=2.153$, 95\% CI: 1.072-4.326). In stage IIIA-NBF1 patients (HR $=5.595,95 \%$ CI: 2.987-10.478) as compared to stage IIA-NBF0. In stage IIB-NBF1 patients ( $\mathrm{HR}=18.142,95 \%$ CI: 11.143-29.537) as compared to stage IIC-NBF0 (HR $=14.397,95 \%$ CI: 8.217-25.224), or IIIB-NBF0 patients (HR $=8.364,95 \%$ CI: 5.594-12.506). The above phenomena indicated that the NBF-TNM stage greatly improved the accuracy of prognostic prediction than the conventional AJCC TNM stage after combining with the NBF-stage, thereby demonstrating that the NBF1-stage exhibited an upstage effect in some patients with the TNM stage of colon cancer. Thus, the prognostic prediction efficacy was found to be robust in patients with non-metastatic colon cancer.

Table 4. Prognosis of NBF-TNM stage in colon cancer.

\begin{tabular}{ccccc}
\hline \multirow{2}{*}{ Stage } & \multirow{2}{*}{ No. of Patients } & \multicolumn{2}{c}{ Cancer-Specific Survival } \\
\cline { 3 - 6 } & & HR (95\% CI) & SE & $p$ Value \\
\hline I NBF0 & 4190 & 1.000 (Referent) & & \\
I NBF1 & 2736 & $3.172(2.009-5.008)$ & 0.233 & $p<0.001$ \\
IIA NBF0 & 2975 & $2.391(1.503-3.801)$ & 0.237 & $p<0.001$ \\
IIA NBF1 & 2670 & $6.570(4.348-9.928)$ & 0.211 & $p<0.001$ \\
IIB NBF0 & 258 & $7.130(3.689-13.781)$ & 0.336 & $p<0.001$ \\
IIB NBF1 & 331 & $18.142(11.143-29.537)$ & 0.249 & $p<0.001$ \\
\hline
\end{tabular}


Table 4. Cont.

\begin{tabular}{ccccc}
\hline \multirow{2}{*}{ Stage } & No. of Patients & \multicolumn{2}{c}{ Cancer-Specific Survival } \\
\cline { 3 - 5 } & & HR (95\% CI) & SE & $p$ Value \\
\hline IIC NBF0 & 223 & $14.397(8.217-25.224)$ & 0.286 & $p<0.001$ \\
IIC NBF1 & 323 & $23.679(14.859-37.736)$ & 0.238 & $p<0.001$ \\
IIIA NBF0 & 748 & $2.153(1.072-4.326)$ & 0.356 & $p<0.001$ \\
IIIA NBF1 & 434 & $5.595(2.987-10.478)$ & 0.320 & $p<0.001$ \\
IIIB NBF0 & 2867 & $8.364(5.594-12.506)$ & 0.205 & $p<0.001$ \\
IIIB NBF1 & 2456 & $13.382(9.005-19.886)$ & 0.202 & $p<0.001$ \\
IIIC NBF0 & 949 & $26.248(17.553-39.249)$ & 0.205 & $p<0.001$ \\
IIIC NBF1 & 989 & $38.634(25.996-57.416)$ & 0.202 & $p<0.001$ \\
IVA NBF0 & 1681 & $61.161(41.193-89.505)$ & 0.194 & $p<0.001$ \\
IVA NBF1 & 1780 & $92.326(63.182-134.911)$ & 0.194 & $p<0.001$ \\
IVB NBF0 & 1435 & $91.451(62.434-133.954)$ & 0.195 & $p<0.001$ \\
IVB NBF1 & 1773 & $121.179(82.852-177.236)$ & 0.194 & $p<0.001$ \\
\hline
\end{tabular}

\section{Discussion}

Nowadays, enormous progress has been made on the cellular and molecular biology level in colon cancer [13,14]. However, only a few studies focused on the prognosis of NBFs. Furthermore, none of them analyzed more than three NBFs in one study, and none of them combined the NBFs with the existing staging system for a superior prognostic prediction and clinical management. In 2013, a large population-based study showed that married patients were at low risk to present with metastatic disease and more likely to receive effective treatment, as compared to the unmarried patients who faced a significantly higher risk of mortality with colon cancer [6]. A similar conclusion was obtained in three studies $[5,9,15]$, and another previous study found that marriage could result in improved cardiovascular, endocrine, and immune function [16]. We also believed that the depression caused by not being married was related to Vascular Endothelial Growth Factor (VEGF), which could stimulate endothelial cell migration, proliferation and proteolytic activity [17]. Reportedly, Medicaid status or no insurance was associated with unfavorable survival $[7,8,15]$. We held the view that the following three reasons might lead to the poor prognosis of Medicaid status: Medicaid beneficiaries are initiating treatment late, or receiving inadequate treatment; adults enrolled in the Medicaid program are likely to be disabled, presenting with psychiatric and/or physical comorbidities; and these patients would encounter various barriers (e.g., transportation, poor psychosocial support) that may hinder receipt of adequate treatment and follow-up care [8]. Furthermore, the current results concerning the prognosis of marital status and insurance status, were in agreement with previous studies. The current analyses also showed that the higher the county-level median household income of patients in one group, the better the prognosis except in the " $19.15 \mathrm{~K}-48.57 \mathrm{~K}$ " group. Furthermore, a lower median household income was found to be associated with poor survival of patients with malignant colon cancer, considering that the patients with low income have a fragile financial support network for coping with the challenges of colon cancer treatment. With regard to the non-uniform effect of income on survival, our results were consistent with a previous study in ovarian cancer [18]. We thought this strange phenomenon was mainly because of the various relief policies provided by the US government to the low-incomes.

In addition, the results of the current study also showed that the other three NBFs (county percentage with a bachelor's degree, unemployment situation, and year of diagnosis) were not significant prognostic factors in multivariate Cox regression analysis.

The AJCC staging system is widely accepted and clinically used worldwide, although it only considers the extent of invasion of the primary tumor, number of lymph nodes, and distant spread [19], and does not consider the other biological factors that influence the prognosis of colon cancer. Although several previous modifications have improved the predictive ability of the stage, it is not yet optimal for the prediction of prognosis. In 2011, AJCC proposed additional refined staging methods based on the other available factors beyond the classic tumor node metastases (TNM) staging [10]. Consequently, 
the need for a comprehensive staging, combined with other biological and non-biological factors is a major concern.

However, to the best of our knowledge, the NBFs have not yet been well studied in the prognosis of colon cancer and the current study is the first to incorporate NBFs into AJCC staging system.

Herein, the new proposed NBF stage (based on marital status, insurance status, and county-level median household income) was demonstrated to be an independent prognostic factor, and all NBF1-stage patients showed significantly increased mortality as compared to the NBF0-stage patients with the same TNM stage. Furthermore, our analyses revealed that NBF1-stage had a 50.4\% increased risk of cancer-specific mortality in colon cancer, which rose to $77.1 \%$ in non-metastatic colon cancer. Distinguishing between stages IIIA-NBF0 and IIIA-NBF1 in the TNM stage IIIA accounted for the improved prognosis of TNM stage IIIA than IIA $[2,10]$.

Moreover, we also found several NBF1-TNM stages exceeded the NBF0-TNM stages with higher TNM stages. Reportedly, a better prognosis was noted in TNM stage I than stage IIIA, in TNM stage IIIA than stage IIA, in TNM stage IIB than stage IIIB, and in TNM stage IIIB than stage IIC [10]. However, the current analysis showed that the cancer-specific mortality was higher in stage I-NBF1 patients as compared to stage IIA-NBF0 or IIIA-NBF0 patients, in stage IIIA-NBF1 patients as compared to stage IIA-NBF0, in stage IIB-NBF1 patients as compared to stage IIC-NBF0, or IIIB-NBF0 patients. Thus, the NBF stage should be incorporated into the conventional AJCC TNM staging system, which is primarily based on several disease-related biological factors. NBF-TNM stage would improve the prognostic prediction in colon cancer, especially non-metastatic colon cancer.

The superior prognosis of several node-positive stages (stage IIIA-NBF0, IIIA-NBF1, IIIB-NBF0, or IIIB-NBF1) than that of several node-negative stages (stage IIC-NBF0, IIC-NBF1, or IIB-NBF1) ascribed a drawback of the AJCC TNM staging system: Some node-negative patients exhibited poor prognosis, and not all patients with node-positive status were associated with poor prognosis [20,21]. In addition, the stage I (T1-T2N0M0)-NBF1-stage had a higher HR than stage IIIA (T1-T2N1M0)-NBF0. Considering almost the same in the T-stage (T1-T2), we suspected that the NBF-1 might be more robust than the node-positive status for indicating a poor prognosis. However, in the clinical treatment, stage IIIA, not stage I, patients are treated with adjuvant chemotherapy [22]. Therefore, the current study suggested the existence of undertreatment in the TNM stage I colon cancer, and overtreatment in the TNM stage IIIA colon cancer. In addition, NBF1-stage could play a role in guiding the application of chemotherapy considering the role of node-positive status in the application of chemotherapy [23,24]. The phenomenon that stage I (T1-T2N0M0)-NBF1 had higher HR than stage IIA (T3N0M0)-NBF0, and stage IIB (T4aN0M0)-NBF1 had higher HR than stage IIC (T4bNOM0)-NBF0, showed that NBF1-stage might be stronger than $\mathrm{T} 3$ and $\mathrm{T} 4 \mathrm{~b}$ stages for indicating a poor prognosis.

Chemotherapy is a critical adjuvant therapy for colon cancer and has been studied extensively in the past decades. Nowadays, it has been widely accepted that TNM stage II with any of the high-risk factors (T4-stage, obstruction, perforation, poorly differentiated histology, $<12$ lymph nodes, the presence of lymphovascular or perineural invasion, or positive margins) should be considered to receive adjuvant chemotherapy [25-29]. However, some researchers reported that patients with stage II colon cancer with any high-risk factors did not exhibit substantial survival benefit from adjuvant chemotherapy [26,30]. Consequently, we proposed that NBF-stage might improve this situation, and some patients with stage II colon cancer with one or some high-risk factors should be spared from adjuvant chemotherapy.

Nevertheless, the present study had several limitations. First, the NBF-TNM stage did not consider other biological prognostic factors, including microsatellite instability status, treatment, and CEA (carcinoembryonic antigen) level, which might affect survival [22,31,32]; thus, NBF-TNM stage necessitates further refinement in future studies. Second, limited by the SEER database, the sample size is relatively small and needs to be enlarged. The longest follow-up time was only 59 months and did not exceed 5 years. Furthermore, our study was based on a US-population, and our results might not apply to other countries. For example, as far as we knew, most of the European health systems 
allowing patients free access to cancer services might greatly reduce the effect of insurance status on survival. Finally, considering the analyses were based merely on retrospective data, prospective clinical studies with respect to NBF-stage were essential for an accurate prediction of prognosis and improvement in clinical management.

\section{Conclusions}

In conclusion, the current study demonstrated that marital status, insurance status, and median household income were significant prognostic factors in colon cancer, while NBF-stage was an independent prognostic factor. Thus, NBFs that are otherwise neglected in clinical practice necessitate intensive focus in future studies. Furthermore, healthcare professionals and institutions in charge of patients with colon cancer, should pay more attention to rectal cancer patients with poor NBFs who may benefit from additional resources and support during their therapy. Taken together, the improved precision of prognostic prediction and the guidance of adjuvant chemotherapy in TNM stage II and stage III colon cancer, strongly support the incorporation of NBF-stage into conventional AJCC TNM staging system.

Supplementary Materials: The following are available online at http:/ / www.mdpi.com/2072-6694/10/8/263/s1, Table S1: Multivariable Cox regression analyses of independent prognostic factors in non-metastatic colon cancer.

Author Contributions: Conceptualization, Q.L. (Qi Liu), Q.L. (Qingguo Li) and X.L.; Data curation, D.L.; Formal analysis, Q.L. (Qi Liu) and Q.L. (Qingguo Li); Funding acquisition, Q.L. (Qingguo Li) and X.L.; Investigation, D.L.; Methodology, Q.L. (Qi Liu); Project administration, X.L.; Resources, Q.L. (Qi Liu) and D.L.; Software, D.L.; Supervision, S.C. and X.L.; Validation, Q.L. (Qingguo Li); Visualization, X.L.; Writing一original draft, Q.L. (Qi Liu); Writing—review \& editing, Q.L. (Qi Liu), S.C., Q.L. (Qingguo Li) and X.L.

Funding: This research was supported by the National Science Foundation of China (No. 81702353 and 81772599) and Shanghai Municipal Natural Science Foundation (17ZR1406400). The funders had no role in the study design, data collection and analysis, decision to publish, or preparation of the manuscript.

Conflicts of Interest: The authors declare no conflict of interest.

\section{References}

1. Siegel, R.L.; Miller, K.D.; Fedewa, S.A.; Ahnen, D.J.; Meester, R.G.S.; Barzi, A.; Jemal, A. Colorectal cancer statistics, 2017. CA A Cancer J. Clin. 2017, 67, 177-193. [CrossRef] [PubMed]

2. Arena, E.A.; Bilchik, A.J. What is the optimal means of staging colon cancer? Adv. Surg. 2013, 47, 199-211. [CrossRef] [PubMed]

3. Dienstmann, R.; Mason, M.J.; Sinicrope, F.A.; Phipps, A.I.; Tejpar, S.; Nesbakken, A.; Danielsen, S.A.; Sveen, A.; Buchanan, D.D.; Clendenning, M. Prediction of overall survival in stage II and III colon cancer beyond tnm system: A retrospective, pooled biomarker study. Ann. Oncol. 2017, 28, 1023-1031. [CrossRef] [PubMed]

4. Stintzing, S.; Tejpar, S.; Gibbs, P.; Thiebach, L.; Lenz, H.J. Understanding the role of primary tumour localisation in colorectal cancer treatment and outcomes. Eur. J. Cancer 2017, 84, 69-80. [CrossRef] [PubMed]

5. Li, Q.; Lu, G.; Liang, L.; Li, X.; Cai, S. The influence of marital status on stage at diagnosis and survival of patients with colorectal cancer. Oncotarget 2015, 6, 985-988. [CrossRef] [PubMed]

6. Aizer, A.A.; Chen, M.H.; Mccarthy, E.P.; Mendu, M.L.; Koo, S.; Wilhite, T.J.; Graham, P.L.; Choueiri, T.K.; Hoffman, K.E.; Martin, N.E. Marital status and survival in patients with cancer. J. Clin. Oncol. 2013, 31, 3869-3876. [CrossRef] [PubMed]

7. Du, X.L.D.M.; Lin, C.C.; Johnson, N.J.; Altekruse, S.A.D. Effects of individual-level socioeconomic factors on racial disparities in cancer treatment and survival. Cancer 2011, 117, 3242-3251. [CrossRef] [PubMed]

8. Koroukian, S.M.; Bakaki, P.M.; Raghavan, D. Survival disparities by medicaid status: An analysis of 8 cancers. Cancer 2012, 118, 4271-4279. [CrossRef] [PubMed]

9. Rodday, A.M.; Parsons, S.K.; Snyder, F.; Simon, M.A.; Llanos, A.A.M.; Warren-Mears, V.; Dudley, D.; Lee, J.H.; Patierno, S.R.; Markossian, T.W. Impact of patient navigation in eliminating economic disparities in cancer care. Cancer 2015, 121, 4025-4034. [CrossRef] [PubMed] 
10. Weiser, M.R.; Gönen, M.; Chou, J.F.; Kattan, M.W.; Schrag, D. Predicting survival after curative colectomy for cancer: Individualizing colon cancer staging. J. Clin. Oncol. 2011, 29, 4796-4802. [CrossRef] [PubMed]

11. Auclin, E.; Zaanan, A.; Vernerey, D.; Douard, R.; Gallois, C.; Laurentpuig, P.; Bonnetain, F.; Taieb, J. Subgroups and prognostication in stage iii colon cancer: Future perspectives for adjuvant therapy. Ann. Oncol. 2017, 28, mdx030. [CrossRef] [PubMed]

12. Liu, Q.; Ma, Y.; Luo, D.; Cai, S.; Li, Q.; Li, X. Real-world study of a novel prognostic scoring system: For a more precise prognostication and better clinical treatment guidance in stages ii and iii colon cancer. Int. J. Colorectal Dis. 2018, 33, 1107-1114. [CrossRef] [PubMed]

13. Alwers, E.; Jia, M.; Kloor, M.; Bläker, H.; Brenner, H.; Hoffmeister, M. Associations between molecular classifications of colorectal cancer and patient survival: A systematic review. Clin. Gastroenterol. Hepatol. 2018. [CrossRef] [PubMed]

14. Okugawa, Y.; Grady, W.M.; Goel, A. Epigenetic alterations in colorectal cancer: Emergingbiomarkers. Gastroenterology 2015, 149, 1204-1225. [CrossRef] [PubMed]

15. Zhang, Q.; Wang, Y.; Hu, H.; Huang, R.; Xie, L.; Liu, E.; Chen, Y.G.; Wang, G.; Wang, X. Impact of socioeconomic status on survival of colorectal cancer patients. Oncotarget 2017, 8, 106121-106131. [CrossRef] [PubMed]

16. Gallo, L.C.; Troxel, W.M.; Matthews, K.A.; Kuller, L.H. Marital status and quality in middle-aged women: Associations with levels and trajectories of cardiovascular risk factors. Health Psychol. 2003, 22, 453-463. [CrossRef] [PubMed]

17. Ferrara, N. The biology of vascular endothelial growth factor. Endocr. Rev. 1997, 18, 4-25. [CrossRef] [PubMed]

18. Cowan, R.A.; Tseng, J.; Ali, N.; Dearie, H.; Murthy, V.; Gennarelli, R.L.; Iasonos, A.; Aburustum, N.R.; Chi, D.S.; Long, K.R. Exploring the impact of income and race on survival for women with advanced ovarian cancer undergoing primary debulking surgery at a high-volume center. Gynecol. Oncol. 2018, 149, 43-48. [CrossRef] [PubMed]

19. Yarbro, J.W.; Page, D.L.; Fielding, L.P.; Partridge, E.E.; Murphy, G.P. American joint committee on cancer prognostic factors consensus conference. Cancer 2000, 88, 1739-1757. [CrossRef]

20. Weiser, M.R.; Landmann, R.G.; Kattan, M.W.; Gonen, M.; Shia, J.; Chou, J.; Paty, P.B.; Guillem, J.G.; Temple, L.K.; Schrag, D. Individualized prediction of colon cancer recurrence using a nomogram. J. Clin. Oncol. 2008, 26, 380-385. [CrossRef] [PubMed]

21. O'Connell, J.B.; Maggard, M.A.; Ko, C.Y. Colon cancer survival rates with the new american joint committee on cancer sixth edition staging. J. Natl. Cancer Inst. 2004, 96, 1420-1425. [CrossRef] [PubMed]

22. Thirunavukarasu, P.; Sukumar, S.; Sathaiah, M.; Mahan, M.; Pragatheeshwar, K.D.; Pingpank, J.F.; Zeh, H.; Bartels, C.J.; Lee, K.K.W.; Bartlett, D.L. C-stage in colon cancer: Implications of carcinoembryonic antigen biomarker in staging, prognosis, and management. J. Nat. Cancer Inst. 2011, 103, 689-697. [CrossRef] [PubMed]

23. Rd, B.A.; Schrag, D.; Somerfield, M.R.; Cohen, A.M.; Figueredo, A.T.; Flynn, P.J.; Krzyzanowska, M.K.; Maroun, J.; Mcallister, P.; Van, C.E. American society of clinical oncology recommendations on adjuvant chemotherapy for stage ii colon cancer. J. Clin. Oncol. 2016, 22, 3408-3419.

24. Ganapathi, A.M.; Speicher, P.J.; Englum, B.R.; Castleberry, A.W.; Migaly, J.; Hsu, D.S.; Mantyh, C.R. Adjuvant chemotherapy for $\mathrm{t} 1$ node-positive colon cancers provides significant survival benefit. Dis. Colon Rectum 2014, 57, 1341-1348. [CrossRef] [PubMed]

25. Casadaban, L.; Rauscher, G.; Aklilu, M.; Villenes, D.; Freels, S.; Maker, A.V. Adjuvant chemotherapy is associated with improved survival in patients with stage II colon cancer. Cancer 2016, 122, 3277-3287. [CrossRef] [PubMed]

26. O'Connor, E.S.; Greenblatt, D.Y.; Loconte, N.K.; Gangnon, R.E.; Liou, J.I.; Heise, C.P.; Smith, M.A. Adjuvant chemotherapy for stage II colon cancer with poor prognostic features. J. Clin. Oncol. 2011, 29, 3381-3388. [CrossRef] [PubMed]

27. Quah, H.M.; Chou, J.F.; Gonen, M.; Shia, J.; Schrag, D.; Landmann, R.G.; Guillem, J.G.; Paty, P.B.; Temple, L.K.; Wong, W.D. Identification of patients with high-risk stage II colon cancer for adjuvant therapy. Dis. Colon Rectum 2008, 51, 503-507. [CrossRef] [PubMed] 
28. Gill, S.; Loprinzi, C.L.; Sargent, D.J.; Thomé, S.D.; Alberts, S.R.; Haller, D.G.; Benedetti, J.; Francini, G.; Shepherd, L.E.; Francois, S.J. Pooled analysis of fluorouracil-based adjuvant therapy for stage ii and iii colon cancer: Who benefits and by how much? J. Clin. Oncol. 2004, 22, 1797-1806. [CrossRef] [PubMed]

29. Sargent, D.J.; Goldberg, R.M.; Jacobson, S.D.; Macdonald, J.S.; Labianca, R.; Haller, D.G.; Shepherd, L.E.; Seitz, J.F.; Francini, G. A pooled analysis of adjuvant chemotherapy for resected colon cancer in elderly patients. N. Engl. J. Med. 2001, 345, 1091-1097. [CrossRef] [PubMed]

30. Verhoeff, S.R.; Van Erning, F.N.; Lemmens, V.E.P.P.; De Wilt, J.H.W.; Pruijt, J.F.M. Adjuvant chemotherapy is not associated with improved survival for all high-risk factors in stage ii colon cancer. Int. J. Cancer J. Int. Du Cancer 2016, 139, 187-193. [CrossRef] [PubMed]

31. Roth, A.D.; Delorenzi, M.; Tejpar, S.; Yan, P.; Klingbiel, D.; Fiocca, R.; D'Ario, G.; Cisar, L.; Labianca, R.; Cunningham, D. Integrated analysis of molecular and clinical prognostic factors in stage ii/iii colon cancer. J. Nat. Cancer Inst. 2012, 104, 1635-1646. [CrossRef] [PubMed]

32. Wolmark, N.; Fisher, B.; Wieand, H.S.; Henry, R.S.; Lerner, H.; Legault-Poisson, S.; Deckers, P.J.; Dimitrov, N.; Gordon, P.H.; Jochimsen, P. The prognostic significance of preoperative carcinoembryonic antigen levels in colorectal cancer. Results from nsabp (national surgical adjuvant breast and bowel project) clinical trials. Ann. Surg. 1984, 199, 375-382. [CrossRef] [PubMed]

(C) 2018 by the authors. Licensee MDPI, Basel, Switzerland. This article is an open access article distributed under the terms and conditions of the Creative Commons Attribution (CC BY) license (http:/ / creativecommons.org/licenses/by/4.0/). 